\title{
Cold exposure promotes obesity and impairs glucose homeostasis in mice subjected to a high-fat diet
}

\author{
PING ZHU $^{1 *}$, ZHI-HUI ZHANG ${ }^{1 *}$, XU-FENG HUANG ${ }^{2}$, YAN-CHUAN SHI $^{3}$, \\ NEETA KHANDEKAR ${ }^{3}$, HE-QIN YANG ${ }^{1}$, SHI-YU LIANG ${ }^{1}$, ZHI-YUAN SONG $^{1}$ and SHU LIN ${ }^{1,2}$ \\ ${ }^{1}$ Department of Cardiology, Southwest Hospital, Third Military Medical University (Army Medical University), \\ Chongqing 400038, P.R. China; ${ }^{2}$ Illawarra Health and Medical Research Institute and School of Medicine, \\ University of Wollongong, Wollongong, NSW 2522; ${ }^{3}$ Neuroscience Division, \\ Garvan Institute of Medical Research, Sydney, NSW 2010, Australia
}

Received March 26, 2018; Accepted August 8, 2018

DOI: $10.3892 / \mathrm{mmr} .2018 .9382$

\begin{abstract}
Cold exposure is considered to be a form of stress and has various adverse effects on the body. The present study aimed to investigate the effects of chronic daily cold exposure on food intake, body weight, serum glucose levels and the central energy balance regulatory pathway in mice fed with a high-fat diet (HFD). C57BL/6 mice were divided into two groups, which were fed with a standard chow or with a HFD. Half of the mice in each group were exposed to ice-cold water for $1 \mathrm{~h}$ /day for 7 weeks, while the controls were exposed to room temperature. Chronic daily cold exposure significantly increased energy intake, body weight and serum glucose levels in HFD-fed mice compared with the control group. In addition, $1 \mathrm{~h}$ after the final cold exposure, c-fos immunoreactivity was significantly increased in the central amygdala of HFD-fed mice compared with HFD-fed mice without cold exposure, indicating neuronal activation in this brain region. Notably, $61 \%$ of these c-fos neurons co-expressed the neuropeptide $Y$ (NPY), and the orexigenic peptide levels were significantly increased in the central amygdala of cold-exposed mice compared with control mice. Notably, cold exposure significantly decreased the anorexigenic brain-derived neurotropic factor (BDNF) messenger RNA (mRNA) levels in the ventromedial hypothalamic nucleus and increased growth hormone releasing hormone (GHRH) mRNA in the paraventricular nucleus. NPY-ergic neurons in the central amygdala
\end{abstract}

Correspondence to: Professor Shu Lin or Professor Zhi-Yuan Song, Department of Cardiology, Southwest Hospital, Third Military Medical University (Army Medical University), 30 Gaotanyan, Shapingba, Chongqing 400038, P.R. China

E-mail: shulin1956@126.com

E-mail: zysong2010@126.com

*Contributed equally

Key words: neuropeptide Y, cold exposure, body weight, obesity, central amygdala were activated by chronic cold exposure in mice on HFD via neuronal pathways to decrease BDNF and increase GHRH mRNA expression, possibly contributing to the development of obesity and impairment of glucose homeostasis.

\section{Introduction}

Obesity is a life-threatening condition that affects $>600$ million patients worldwide (1). Obesity has become a global public health issue and is a major contributor to numerous diseases (2). Over the past four decades, global obesity prevalence displayed an increasing trend. If the present trends continue, global obesity prevalence is expected to reach $18 \%$ in men and surpass $21 \%$ in women by 2025 (1). Notably, the proportion of patients with obesity in the north of the Northern hemisphere is greater than in the south, with the highest proportion being observed in the northeast region $(1,3,4)$. While there are numerous reasons such as diet (5) for the aforementioned geographical variations, it is worth noting that the northern regions of the Northern hemisphere [where the obesity incidence and body mass index (BMI) are highest] are significantly colder than the southern regions. These observations are consistent with Bergmann's rule, which states that, within a polytypic warm-blooded species, body size increases with decreasing the mean temperature of its habitat (6).

In contrast to findings of higher obesity rates or BMIs in colder climates, cold exposure has recently been proposed as an intervention for the prevention and management of obesity. This is associated with the effect of cold exposure to engage metabolically active adipose tissue. There are three different types of adipose tissue in humans and animals, namely white adipose tissue (WAT), brown adipose tissue (BAT) and beige adipose tissue (BeAT) (7). BeAT is sometimes called brite adipose tissue (brown in WAT) or recruitable BAT (rBAT), as it resembles classical brown adipocytes within predominantly WAT and the fact quantity of BeAT in the body is augmented by cold exposure (8). BAT and BeAT are both able to use glucose and fatty acids for non-shivering thermogenesis through the action of transmembrane proteins in mitochondria that uncouple fuel oxidation by maintaining a protein gradient producing heat, notably uncoupling 
protein 1 (UCP-1). The action of UCP-1 in BAT and BeAT increases body temperature while consuming energy. Thus, an increase in BAT mass may prevent the development of obesity $(9,10)$. Cold exposure has been shown to increase the expression levels of UCP-1 in BAT and BeAT in humans $(11,12)$. This change is associated with an increase in non-shivering thermogenesis and energy expenditure. Cold exposure is a promising method of reducing obesity while also reducing whole body insulin resistance and improving glucose metabolism in humans $(13,14)$. These benefits have been proposed to occur via cold stimulation-induced activation of sympathetic neural pathways through BAT and BeAT (15).

Despite the aforementioned reports of cold exposure in mice and humans leading to activation of BAT and BeAT, it is also conceivable that cold exposure could lead to adverse metabolic outcomes. Notably, subjecting the body to cold is a 'stressful' condition that activates the sympathetic nervous system (16). This not only activates BAT (15) but also activates feeding-related mechanisms (17). For example, under cold stress and during fasting, agouti related peptide (AgRP) neurons in the hypothalamic arcuate nucleus are activated to promote feeding behavior (17). Such a mechanism could potentially counteract the effect of increased energy expenditure to induce weight loss by increasing food intake.

In order to clarify the effect of chronic cold exposure on energy balance and glucose homeostasis, and to elucidate the potential central mechanisms responsible for any of these effects, the present study investigated the effects of chronic cold exposure in mice subjected to daily cold exposure $(1 \mathrm{~h}$ standing in ice-cold water) on energy intake, body weight, adipose tissue mass, glucose and insulin tolerance, as well as the potential underlying neuronal pathways. The present neuronal investigations were focused on the central amygdala and hypothalamus, since the central amygdala is a key brain area involved in the neural circuitry of stress responses (18), while the hypothalamus is the main site of the brain modulating feeding behavior and energy homeostasis, and both areas are interconnected (19). Particularly, the neurotransmitters of interest were neuropeptide Y (NPY) and brain-derived neurotropic factor (BDNF). NPY is prominently produced in the central amygdala and the arcuate hypothalamic nucleus (ARC), while BDNF is mainly expressed in the ventromedial hypothalamic nucleus (VMH). NPY stimulates (20) while BDNF reduces food intake $(21,22)$. In addition, hypothalamic NPY was considered a 'stress molecule' that is upregulated throughout various regions of the brain, including the central amygdala and hypothalamus, in response to cold stress $(23,24)$. The present study also investigated growth hormone releasing hormone (GHRH), because it is known that neurons from the amygdala project to GHRH neurons in the paraventricular nucleus (PVN), and GHRH is an important regulator of peripheral glucose metabolism (25). The present study investigated mice that were fed either a standard chow diet or a high-fat diet (HFD), since hypothalamic NPY expression is upregulated not only by cold stress but also by HFD $(26,27)$, and overexpression of NPY in the brain affects peripheral metabolism, including insulin resistance, thereby potentially revealing possible changes in response to cold stress.

\section{Materials and methods}

Ethics statement and general animal care. All animal experimental protocols were approved by the Third Military Medical University Animal Care Committee (Chongqing, China) and were performed according to the National Institutes of Health (NIH) Guide for the Care and Use of Laboratory Animals (NIH publication no. 8023). A total of 56 mice (C57BL/6) were used in the study (28 mice for the in vivo investigations of energy intake, body weight, adipose tissue mass, glucose and insulin tolerance, and in situ hybridization (Fig. 1A). In total, 28 mice were used for investigations of central c-fos expression, and 28 transgenic mice expressing green fluorescent protein (GFP) under the control of the NPY promoter (Npy-hrGFP mice, stock no. 006417, which had been obtained from the Jackson Laboratory, Bar Harbor, ME, USA and further bred in our facility.) were used to determine whether NPY neurons in NPY-GFP mice were activated by cold exposure and HFD. All mice were housed under conditions of controlled temperature $\left(22^{\circ} \mathrm{C}\right)$ and illumination (12 h light-dark cycle, starting at $\left.7 \mathrm{am}\right)$ with ad libitum access to water and standard chow (Gordon's Specialty Stock Feeds, Yanderra, New South Wales, Australia). The standard chow diet provided $8 \%$ of energy from fat, $21 \%$ from protein and $71 \%$ from carbohydrates, with a total energy content of $10.88 \mathrm{~kJ} / \mathrm{g}$.

HFD, cold exposure, and measurement of their effects on body weight and food intake. At 10 weeks of age, the 56 mice to be used in the present study were transferred from housing conditions of 3-4 mice per cage to individual cages. Half of the mice were fed a standard chow diet, while the other half were fed a HFD (Gordon's Specialty Stock Feeds), which provided 23.0\% of energy from fat, $19.4 \%$ from protein, $48.2 \%$ from carbohydrates, $4.7 \%$ from crude fiber, $4.7 \%$ from acid detergent fiber, with a total energy content of $19.98 \mathrm{~kJ} / \mathrm{g}$. Half of the mice on each diet were left to stand in ice-cold water, which was $0.5 \mathrm{~cm}$ in depth, for $1 \mathrm{~h}$ per day for 7 weeks. Non-cold exposed mice also stood on the water but at room temperature. 28 of the mice were weighed at the same time of the day once per week. Food intake was measured over $24 \mathrm{~h}$ when mice were 10, 12, 14 and 17 weeks of age (Fig. 1B). Energy intake (kJ/day) was calculated as [(weight of food placed in the hopper)-(weight of food remaining in the hopper after $24 \mathrm{~h}$ )]x(energy density of food in $\mathrm{kJ} / \mathrm{g})]$.

Measurement of effects of HFD and cold exposure on glucose and insulin tolerance. At 16 weeks of age, i.e., 6 weeks after commencing HFD and cold exposure interventions, the mice were fasted for $16 \mathrm{~h}$ and injected intraperitoneally with a $10 \%$ D-glucose solution at a dose of $1.0 \mathrm{~g}$ per kg body weight. Blood samples were collected from the tip of the tail at $0,15,30$, 60 and 90 min after glucose administration, and blood glucose levels were measured using a glucometer (Accu Check II; Roche, Castle Hill, New South Wales, Australia). Two days later, the mice were fasted for $6 \mathrm{~h}$ from 8:00 a.m. and were injected intraperitoneally with insulin at a dose of $1.0 \mathrm{IU}$ per kg body weight. Blood samples were obtained from the tail tip at $0,15,30$ and $60 \mathrm{~min}$ after insulin injection for determination of glucose levels as stated above. Cold exposure was performed subsequently to the glucose and insulin tolerance tests on the same day. 


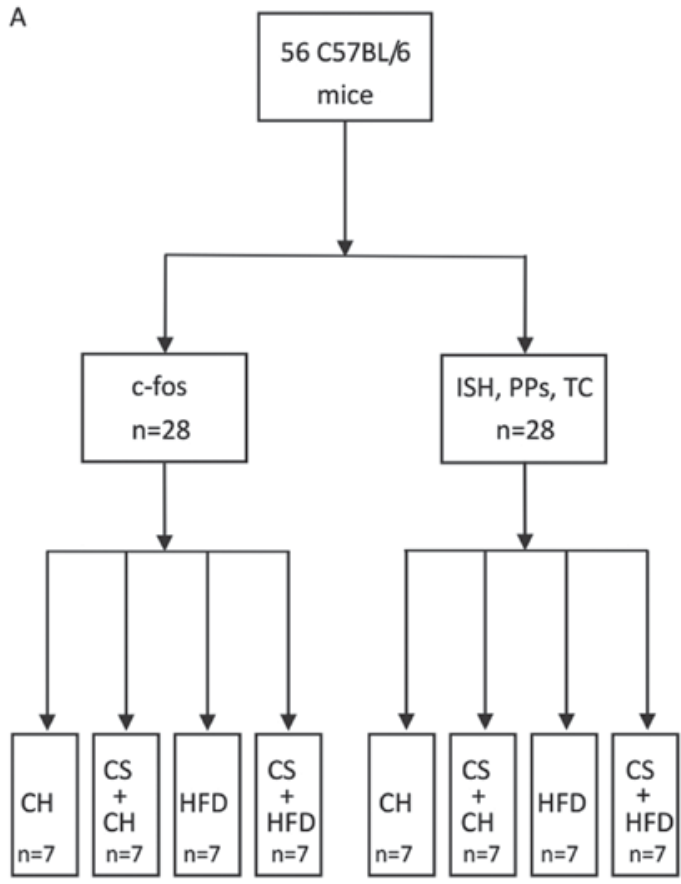

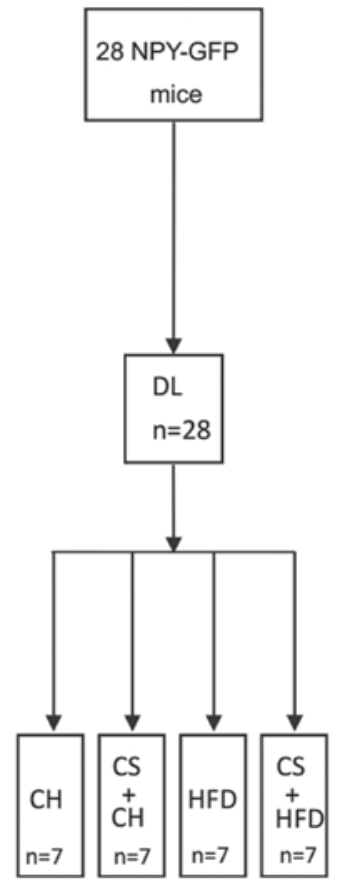

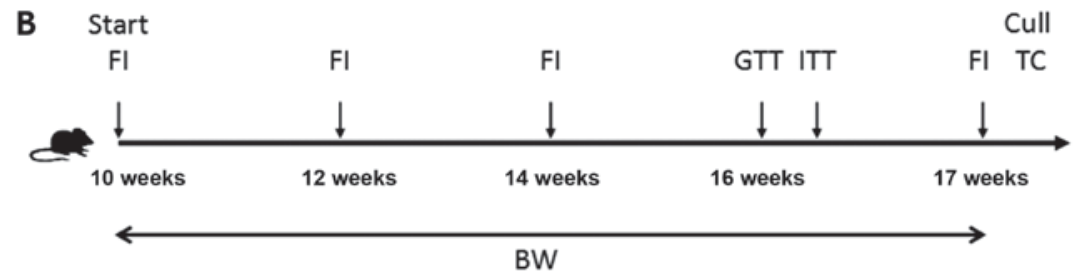

Figure 1. Flowchart of the methodology employed in the present study. (A) Animal groupings. (B) Timeline of the experiments performed. CH, standard chow diet; CS, cold stress; HFD, high-fat diet; c-fos, c-fos immunoreactivity test; ISH, in situ hybridization; PPs: physiological parameters testing; TC, tissue collection; BW, body weight; FI, food intake; GTT, glucose tolerance test; ITT, insulin tolerance test.

Tissue collection upon HFD and cold exposure. At 17 weeks of age, 5 days after the insulin tolerance tests, a total of 28 of the mice from the four experimental groups mentioned above were sacrificed by cervical dislocation followed by decapitation. The brain was removed and frozen on an aluminium plate on dry ice, and then stored at $-70^{\circ} \mathrm{C}$ until in situ hybridization. The interscapular BAT as well as WAT depots (inguinal, epididymal, mesenteric and retroperitoneal) were removed and weighed $(17,28)$. The weights of these WAT depots were summed together and expressed as total WAT weight.

Determination of changes inc-fos immunoreactivity in the central amygdala in response to HFD and cold exposure. The remaining 28 mice from the four experimental groups were used for this experiment (Fig. 1). Upon anesthesia with $100 \mathrm{mg} / \mathrm{kg}$ ketamine and $20 \mathrm{mg} / \mathrm{kg}$ xylazine (Parke Davis-Pfizer, Sydney, New South Wales, Australia and Bayer AG, Leverkusen, Germany, respectively), mice were perfused via the left cardiac ventricle with saline and then $4 \%$ paraformaldehyde. The brain was removed and soaked in a solution of $30 \%$ sucrose overnight, prior to being cut into $30-\mu \mathrm{m}$ thick coronal sections using a microtome. Brain c-fos immunoreactivity was detected via immunohistochemistry using techniques described previously (29). The number of cells exhibiting positive c-fos immunoreactivity was counted using a Zeiss Axioplan light microscope (Carl Zeiss Imaging Solutions GmbH, Munich, Germany).
Effect of HFD and cold exposure on NPY-expressing neurons in the central amygdala. In order to investigate how NPY neurons in the central amygdala respond to HFD and cold exposure, 28 transgenic mice expressing GFP under the control of the mouse NPY promoter (NPY-GFP mice) were used. The brain tissues from these mice, upon exposure to ultraviolet light, displayed fluorescence emission in all or the majority of known NPY neurons in the brain (30). For double labeling co-localization experiments, 5 mice from the cold exposure with HFD group were exposed to cold stress as described above for $1 \mathrm{~h}$ per day for 7 weeks, and were then sacrificed by cervical dislocation and decapitation subsequent to perfusion. The brains were dissected, placed overnight in $30 \%$ sucrose, and cut into coronal sections of $30 \mu \mathrm{m}$ thickness using a microtome. Upon rinsing in PBS, the slides were incubated with the primary antibody rabbit anti-mouse c-fos (diluted at 1:2,000; Santa Cruz Biotechnology Inc., Dallas, TX, USA). Next, the secondary antibody Alexa Fluor ${ }^{\circledR} 594$ goat anti-rabbit immunoglobulin G (A11037; Life Technologies; Thermo Fisher Scientific, Inc., Waltham, MA, USA) diluted at 1:250 was added. Red c-fos stain in the c-fos immunohistochemistry test and GFP-positive neurons in GFP-NPY transgenic mice were visualized and counted under a Zeiss Axiophot microscope (Imaging Solutions GmbH).

In situ hybridization to determine the mRNA expression of $B d n f$ and Ghrh in the VMH and PVN, respectively, in response 
Table I. Effect of cold exposure and HFD on glucose metabolism.

\begin{tabular}{lccrr}
\hline Area under the curve & $\mathrm{CH}$ & $\mathrm{CS}+\mathrm{CH}$ & HFD & CS+HFD \\
\hline GTT $(\mathrm{mmol} / 1 / 90 \mathrm{~min})$ & $1,095.64 \pm 12.3$ & $1,171.93 \pm 16.6^{\mathrm{a}}$ & $1,352.36 \pm 18.7^{\mathrm{a}, \mathrm{b}}$ & $1,405.39 \pm 22.6^{\mathrm{a}, \mathrm{b}}$ \\
ITT $(\mathrm{mmol} / 1 / 60 \mathrm{~min})$ & $428.40 \pm 12.7$ & $422.20 \pm 7.9$ & $560.25 \pm 14.9^{\mathrm{a}, \mathrm{b}}$ & $573.88 \pm 10.6^{\mathrm{a}, \mathrm{b}}$ \\
\hline
\end{tabular}

Values are presented as the mean \pm standard error of the mean. ${ }^{\mathrm{a}} \mathrm{P}<0.01 \mathrm{vs}$. Chow group; ${ }^{\mathrm{b}}<0.01 \mathrm{vs}$. Cold stress + chow group. $\mathrm{CH}$, standard chow diet; CS, cold stress; HFD, high-fat diet; GTT, glucose tolerance test; ITT, insulin tolerance test.

to HFD and cold exposure. The frozen brain tissues collected were used for radioactive in situ hybridization. For that purpose, DNA oligonucleotides complementary to mouse $B d n f$ (5'-CCGAACCTTCTGGTCCTCATCCAGCAGCTC TTCGATGACGTGCTCA-3') and Ghrh (5'-GCTTGTCCT CTGTCCACATGCTGTCTTCCTGGCGGCTGAGCC TGG-3'), were used, which were labeled with $\left[{ }^{35} \mathrm{~S}\right]$ thio-dATP (Amersham Biosciences UK, Ltd., Little Chalfont, UK) using terminal deoxynucleotidyl transferase (Roche, Mannheim, Germany). The mRNA expression levels of Bdnf and Ghrh were evaluated by measuring silver grain densities over individual neurons from photo-emulsion-dipped sections, as described previously (31).

Statistical analysis. Data were presented as the mean \pm standard error of the mean. Two-way analysis of variance (ANOVA) was used for analysis of body weight, energy intake, glucose levels, tissue weight, BAT weight, c-fos, NPY, Bdnf mRNA and Ghrh mRNA expression levels considering cold exposure and dietary effects. Two-way repeated ANOVA was used to analysis body weight and energy intake data. GraphPad Prism 6 software (GraphPad Software, Inc., La Jolla, CA, USA) was used to analyze the levels of mRNA expression. Bonferroni post hoc multiple comparison tests were performed following ANOVA to identify differences among means. $\mathrm{P}<0.05$ was considered to indicate a statistically significant difference.

\section{Results}

Synergetic effect of cold exposure and HFD on body weight and food intake. To evaluate the effect of different diets and cold exposure, the body weight and food intake of mice were measured weekly. During 7 weeks of treatment, all the mice gained weight but at different rate. Chow-fed mice exposed to cold displayed a higher weight gain than chow-fed mice at room temperature. Similarly, cold exposure in HFD-fed mice led to more weight gain than exposure to room temperature, which implied that cold exposure on HFD induced weight gain in the mice. There is one obvious difference between the two groups of mice that were exposed to cold condition for $1 \mathrm{~h}$, i.e., the body weight of HFD-fed mice was larger than the body weight of chow-fed mice. In addition, among the four groups of mice, the HFD-fed mice exposed to cold were the heaviest (Fig. 2A). Thus, HFD intensified the effect of cold exposure on body weight in mice. By measuring food intake of mice regularly, the weight growth curve of mice was similar to the increasing curve of food intake, which suggested that weight gain and food intake were positively correlated (Fig. 2B). The outcome suggested the extra energy received by mice may increase energy storage as fat in the body, thus increasing the body weight in these mice.

Cold exposure worsens glucose metabolism in HFD-fed mice. The mice that suffered cold exposure stored more energy than those without cold exposure. Combined with HFD, the mice exposed to cold were prone to become obese. To investigate whether cold exposure and HFD affected glucose metabolism and the function of insulin, glucose and insulin tolerance tests were carried out. In the standard chow-fed mice, the cold exposure group exhibited significant slower glucose clearance ability than mice without chronic cold exposure. Remarkably, the HFD-fed mice that experienced cold displayed the worst glucose tolerance (Fig. 2C), which was consistent with the areas under the glucose tolerance curves results (Table I). In addition, by measuring blood glucose level following injection of insulin, it was observed that there was no significant difference between mice exposed to cold and mice without cold exposure on standard chow diet. However, the blood glucose level of HFD-fed mice was notably higher than that of standard chow-fed mice (Fig. 2D). The areas under the insulin tolerance curves showed the same results (Table I). These results indicated that HFD made mice less sensitive to insulin.

Cold exposure and HFD result in greater WAT weight in mice. Cold exposure and HFD have an additive effect on body weight and energy intake of mice. To clarify if the extra energy received by the mice was converted into chemical energy, stored as fat in the body, and thus increase body weight in these mice, we measured BAT and WAT depots (inguinal, epididymal, mesenteric and retroperitoneal) upon dissection. The two groups of mice subjected to cold exposure daily and HFD showed markedly higher total WAT mass than standard chow-fed mice (Fig. 3A). The BAT masses did not differ among the four groups (Fig. 3B).

Chronic cold exposure activates neurons in the central amygdala of mice on HFD. According to the results shown above, HFD and cold exposure induced an adverse metabolic phenotype. To identify possible mechanisms for this phenomenon, the present study investigated the effects of HFD and cold exposure on the expression of c-fos, an early marker of neuronal activation, in the central amygdala, a stress-responsive region of the brain that is connected with brain regions that influence energy homeostasis. In standard chow-fed mice, the cold exposed group was observed to have significantly more c-fos-positive neurons in the central amygdala than the standard chow mice without cold exposure. Furthermore, in the same region of the central amygdala, HFD-fed mice also exhibited more labeled 

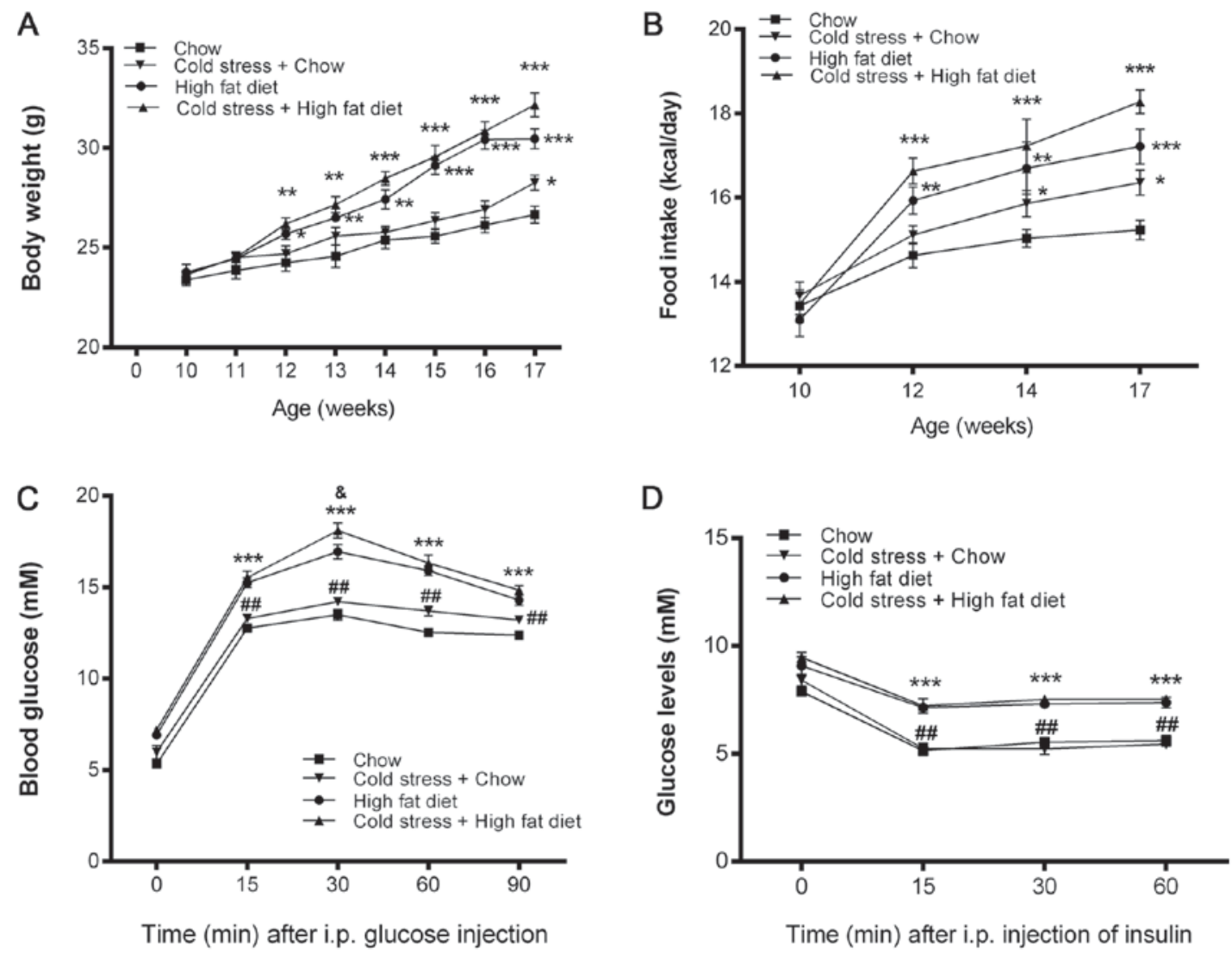

Figure 2. Effect of HFD and cold stress on (A) body weight ( $n=7$ mice per group) and (B) energy intake ( $n=7$ mice per group. Effect of cold stress and HFD on (C) blood glucose ( $\mathrm{n}=7$ mice per group) and (D) insulin tolerance ( $\mathrm{n}=5-6$ mice per group). ${ }^{*} \mathrm{P}<0.05,{ }^{* *} \mathrm{P}<0.01$ and ${ }^{* * * *} \mathrm{P}<0.001$ vs. Chow; ${ }^{\# \#} \mathrm{P}<0.01$ vs. cold stress + HFD; ${ }^{\circledR} \mathrm{P}<0.05$ vs. HFD. HFD, high-fat diet; i.p., intraperitoneal.
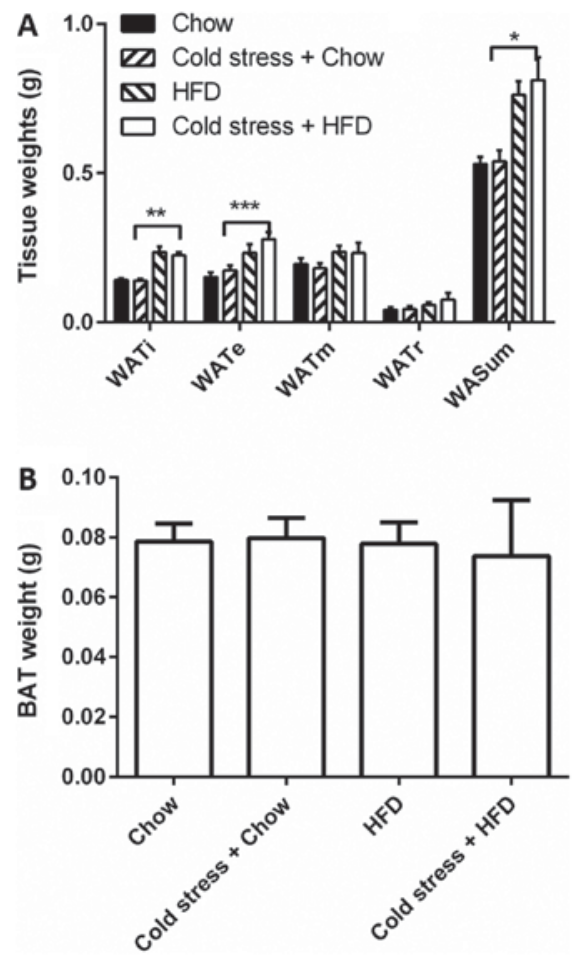

Figure 3. Effect of cold stress and HFD on (A) WAT and (B) BAT. Data are presented as the mean \pm standard error of the mean ( $n=7$ mice per group). ${ }^{*} \mathrm{P}<0.05,{ }^{* *} \mathrm{P}<0.01$ and ${ }^{* * *} \mathrm{P}<0.001$, as indicated. HFD, high-fat diet; BAT, brown adipose tissue; WAT, white adipose tissue; WATi, inguinal WAT; WATe, epididymal WAT; WATm, mesenteric WAT; WATr, retroperitoneal WAT; WASum, total WAT mass.

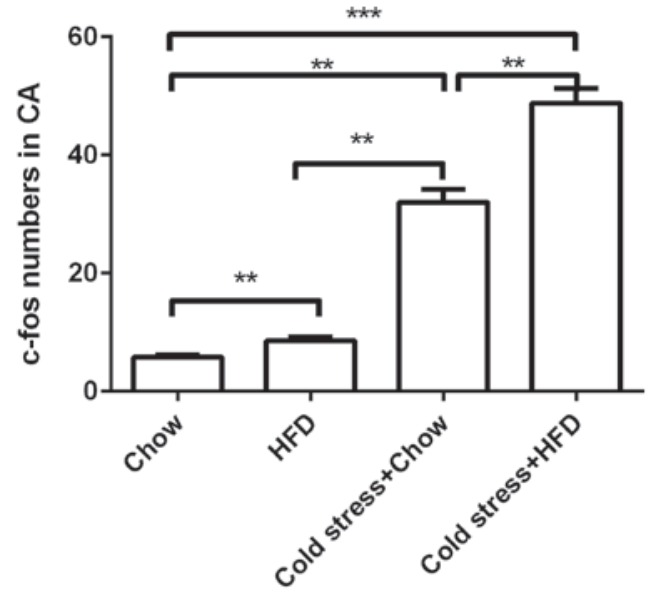

Figure 4. Different c-fos immunoreactivity in the CA in response to cold stress with or without HFD. Data are presented as the mean \pm standard error of the mean ( $\mathrm{n}=7$ mice per group). ${ }^{* *} \mathrm{P}<0.01$ and ${ }^{* * *} \mathrm{P}<0.001$, as indicated. HFD, high-fat diet; CA, central amygdala.

c-fos-positive neurons than that standard chow-fed mice (Fig. 4). These results suggested that cold exposure and HFD activated the central neuronal system, which stimulated the central amygdala neurons at an early stage.

NPY neurons in NPY-GFP mice are activated by cold exposure and HFD. The results from examining c-fos activity verified that cold exposure and HFD excited neurons in the central 

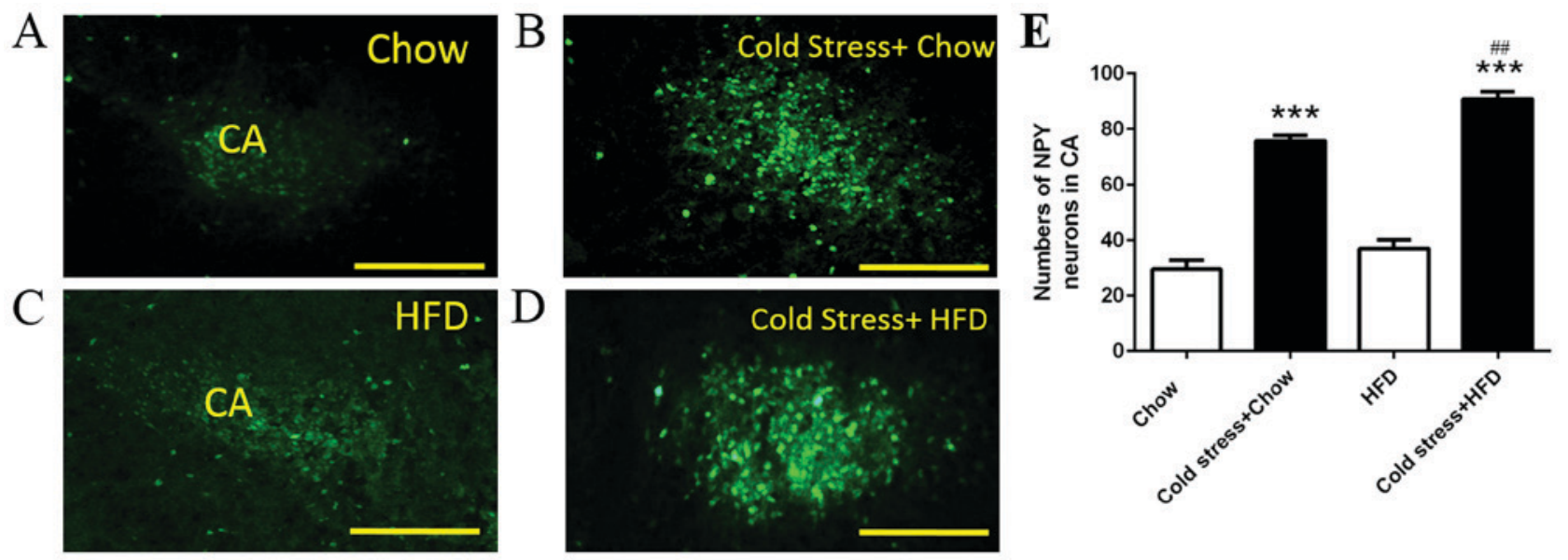

Figure 5. Different number of positive NPY-green fluorescent protein neurons in the CA in response to cold stress and/or HFD. (A) Chow, (B) cold stress + chow, (C) HFD, (D) cold stress + HFD and (E) quantification. Data are presented as the mean \pm standard error of the mean ( $\mathrm{n}=7$ mice per group). Scale bars, $60 \mu \mathrm{m}$. ${ }^{* * * *} \mathrm{P}<0.001$ vs. chow; ${ }^{\# \#} \mathrm{P}<0.01$ vs. cold stress + chow. CA, central amygdala; NPY, neuropeptide $\mathrm{Y}$.

amygdala, which suggested that the activated neurons excreted NPY, which affected blood glucose metabolism. To confirm if NPY in mice subjected to cold exposure and HFD was involved in regulating blood glucose level, which subsequently resulted in obesity, the present study investigated brain sections. The two groups without cold exposure showed no difference in NPY neurons in the central amygdala between HFD-fed mice and standard chow-fed mice $(\mathrm{P}=0.138)$. For the two groups of mice fed with HFD, mice with cold exposure displayed more NPY neurons than mice without cold exposure. It was observed that the section of the central amygdala in the two cold exposure mice group had more activated NPY neurons in the HFD-fed mice than in the standard chow-fed mice (Fig. 5). Unexpectedly, the section of the central amygdala in mouse brain showed that $61 \%$ of the c-fos-positive neurons were positive for NPY (Fig. 6), which suggested that NPY neurons in the central amygdala are highly activated by cold exposure and HFD.

$H F D$ and cold exposure suppresses expression of Bdnf $m R N A$ while inducing that of Ghrh $m R N A$. By visualizing the sliced sections of NPY-GFP mouse brain, it was observed that the numbers of the central amygdala NPY neurons increased in mice under cold exposure and HFD. It is well known that central amygdala neurons project to their downstream neurons in the VMH and PVN. To identify the mechanism of cold exposure and HFD leading to obesity, the expression of $B d n f$ mRNA and Ghrh mRNA was tracked. Compared to standard chow-fed mice, neither cold exposure nor HFD suppressed the expression of $B d n f$ mRNA. Furthermore, combining with HFD, cold exposure led to the lowest level of $B d n f$ mRNA expression (Fig. 7A). Regarding the expression of Ghrh mRNA, mice that suffered cold exposure or HFD showed higher expression than standard chow-fed mice. Thus, the mice subjected to cold exposure together with HFD displayed the highest mRNA expression levels of Ghrh (Fig. 7B).

\section{Discussion}

In recent years, cold exposure has been investigated as a potential means of combating obesity due to its ability to activate BAT, leading to increased energy expenditure through UCP-1-mediated non-shivering thermogenesis (32). However, the outcome of our study was not consistent with the theory that cold exposure may contribute to obesity reduction. Under conditions of cold exposure, chow-fed mice received in more energy than mice maintained at room temperature. Furthermore, cold exposure coupled with HFD induced a more pronounced obese phenotype than either cold exposure or HFD alone, which was consistent with the results of Kuo et al (33).

Humans protect themselves from cold using appropriate clothes and living in heated environments. Concerning this self-protective behavior during our daily life, it is unlikely that human beings are exposed to a cold surrounding for a long period, but transmigrate from cold to warm environments in occasions. Frequently, parts of the human body suffer from cold exposure during winter. Stress has been demonstrated to change feeding responses in a bidirectional pattern, with both increases and decreases in intake observed. The effects of stress on food intake regulation are dependent on the type of the stressor $(34,35)$. The present study observed that mice fed with a HFD and subjected to conditions of cold showed significant increases energy intake, and this corresponded to significant increases in body weight and WAT mass compared to standard chow mice. The present observations indicate that, although previous work has shown that cold-induced BAT activation increases energy expenditure $(10,12)$, increased energy intake having overcompensated for any increase in energy expenditure related to cold exposure.

One region of the brain that is implicated in exerting protective effects from stressors such as cold is the amygdala, which is located in the medial temporal lobe and forms part of the limbic system $(36,37)$. Animal studies have shown that the central amygdala, specifically, is largely involved in stress-related responses $(38,39)$. This is in line with our current finding that cold exposure induced an increase in c-fos immunoreactivity in the central amygdala of mice. Furthermore, an increase in the dietary intake observed when mice were fed with HFD during chronic conditions of cold exposure could be due to the possibility 
A

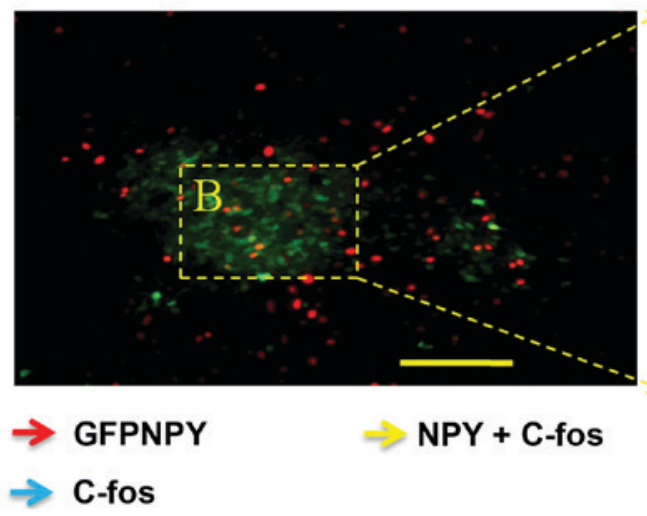

B

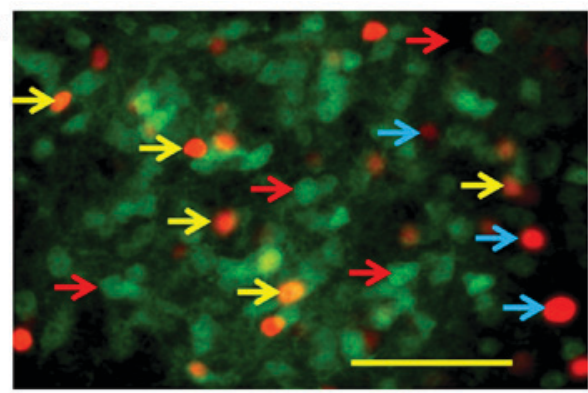

Scale bar: $A=25 \mu \mathrm{m}, B=100 \mu \mathrm{m}$

Figure 6. Cold-stress with high-fat diet induces c-fos expression in the central amygdala. Co-localization (61\%) in mice exposed to cold stress with high-fat diet for 7 weeks. Scale bars, (A) $25 \mu \mathrm{m}$, and (B) $100 \mu \mathrm{m}$. NPY, neuropeptide Y; GFP, green fluorescent protein.
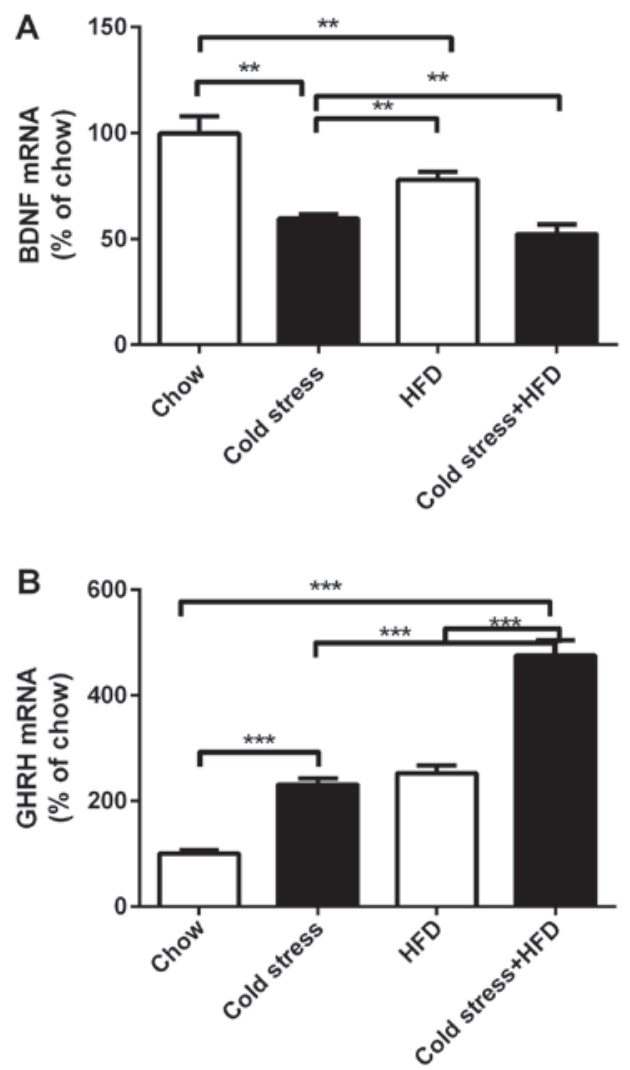

Figure 7. (A) Quantification of BDNF mRNA in the ventromedial hypothalamic nucleus expressed as a percentage of standard chow-fed mice. (B) Quantification of GHRH mRNA in the paraventricular nucleus expressed as a percentage of standard chow-fed mice. Data are presented as the mean \pm standard error of the mean ( $n=7$ mice per group). ${ }^{* *} \mathrm{P}<0.01$ and ${ }^{* * *} \mathrm{P}<0.001$, as indicated. HFD, high-fat diet; BDNF, brain-derived neurotropic factor; GHRH, growth hormone releasing hormone.

that the central amygdala responses in stressful conditions may occur via orexigenic neuropeptides known to harbour abundant NPY neurons $(40,41)$, which are critically involved in regulating energy metabolism and adiposity by promoting fat accumulation (42). Our observations showed that c-fos immunoreactivity and NPY neuronal immunoreactivity were co-localized within the central amygdala, suggesting that activation of NPY neurons occurs in response to cold acclimatization stress. This activation of NPY neurons in the central amygdala could have contributed to the phenotype observed in our HFD-fed cold-exposed mice. Cold exposure stimulates NPY neurons in NPY-GFP mice to produce more NPY. As a feeding promoter, the increased NPY enlarged the orexigenic effect. Mice subjected to HFD combined with cold exposure, which is similar to modern human lifestyle, are more likely to develop obesity.

Our observations of increased activity of NPY neurons in the central amygdala of GFP mice supports the idea that these neurons possibly cause stress-induced release of NPY, which may be implicated in promoting angiogenesis and adipogenesis, leading to exacerbation of diet-induced obesity and glucose intolerance as observed by others $(33,43,44)$.

In conjunction to affecting the NPY systems in the central amygdala, it is important to note that central amygdala projections innervate the regions of the hypothalamus, particularly the VMH and the PVN (45). One of the factors important in energy metabolism is the BDNF, which is abundantly expressed in the PVN and VMH of the hypothalamus. It has been previously reported that BDNF exerts hypophagic and weight reducing effects in animals (46). Furthermore, BDNF in the central nervous system can influence glucose metabolism directly, leading to magnification of the insulin function in peripheral tissues (47). Peripheral BDNF rapidly enhanced insulin signal transduction in liver and performed hypoglycemic action in diabetic mice (48). BDNF is mainly expressed in the $\mathrm{VMH}$, which were significantly reduced in response to HFD and cold exposure, possibly contributing to the increased energy intake and altered glucose homeostasis observed in these mice. Another factor that is influenced by neuronal projections from the central amygdala is GHRH, which is abundantly expressed in the ARC, VMH and PVN regions of the hypothalamus $(49,50)$. It has been shown that GHRH can stimulate the pituitary gland to release growth hormone (GH). GH can promote the decomposition of glycogen (51), and inhibit glucose utilization by muscle and adipose tissue (52). In addition, GHRH actively modulates glucose homeostasis by facilitating insulin action and normalizing glucose metabolism in obese mice, irrespective of dietary intake (47). The present study observed that HFD or cold exposure can independently and additively increase the levels of Ghrh mRNA expression in the PVN. This change, combined with reduced VMH $B d n f$ mRNA levels in response to HFD and cold exposure, could have 
contributed to the hyperphagia, weight gain and imbalances in glucose and insulin responses in the mice of the present study.

In summary, while there previous reports have suggested potential therapeutic values in manipulating BAT or BeAT for the management of diabetes and obesity (53), it is important to note that the use of cold exposure to activate BAT or BeAT needs to be carefully considered, in light of our current findings that cold exposure (with the current paradigm, at least), may cause undesired physiological responses. Further studies are required using cold exposure at different intensities and durations in order to reveal the full association between cold exposure and energy/glucose homeostasis. Potential adverse effects should be taken into consideration when manipulating temperature to stimulate the browning of white fat. Although our findings are consistent with an earlier study showing that cold exposure exacerbates HFD-induced obesity (43), we cannot rule out the possibility that our observations are the net outcome of ice-cold exposure and individual housing-induced stress, that is, single housing in the current study may contribute to the ice-cold stress-induced obesity in DIO (Diet induced obesity) mice. Further studies using a different spectrum of cold exposure condition such as $4^{\circ} \mathrm{C}$ in grouped housed mice will provide a better understanding of the impacts of cold exposure on diet-induced obesity.

\section{Acknowledgements}

The authors would like to thank Professor Amanda Sainsbury (The Boden Institute of Obesity, Nutrition, Exercise \& Eating Disorders Honorary Associate, School of Psychology, the University of Sydney, Sydney, New South Wales, Australia) for her critical review of the manuscript.

\section{Funding}

The present study was supported by the National Natural Science Foundation of China (grant nos. 81570300, 81670402 and 81570395).

\section{Availability of data and materials}

The datasets used and/or analyzed during the current study are available from the corresponding author on reasonable request.

\section{Authors' contributions}

$\mathrm{PZ}$ and $\mathrm{ZZ}$ performed the experiments and drafted the manuscript. XH, YS, NK, HY and SYL analyzed and interpreted the data. XH and YS revised the manuscript. SL and ZS designed the present study and revised the paper.

\section{Ethics approval and consent to participate}

All animal experimental protocols were approved by the Third Military Medical University Animal Care Committee (Chongqing, China).

\section{Patient consent for publication}

Not applicable.

\section{Competing interests}

The authors declare that they have no competing interests.

\section{References}

1. NCD Risk Factor Collaboration (NCD-RisC): Trends in adult body-mass index in 200 countries from 1975 to 2014: A pooled analysis of 1698 population-based measurement studies with 19.2 million participants. Lancet 387: 1377-1396, 2016.

2. Must A, Spadano J, Coakley EH, Field AE, Colditz G and Dietz WH: The disease burden associated with overweight and obesity. JAMA 282: 1523-1529, 1999.

3. Wan Y, Jiang X, He Y, Zhang Y, Liang Y, Pan F, Xu Y and Shang L: Body mass index of young men in China: Results from four national surveys conducted between 1955 and 2012. Medicine (Baltimore) 95: e2829, 2016.

4. Moon G, Quarendon G, Barnard S, Twigg L and Blyth B: Fat nation: Deciphering the distinctive geographies of obesity in England. Soc Sci Med 65: 20-31, 2007.

5. Batis C, Mendez MA, Gordon-Larsen P, Sotres-Alvarez D, Adair L and Popkin B: Using both principal component analysis and reduced rank regression to study dietary patterns and diabetes in Chinese adults. Public Health Nutr 19: 195-203, 2016.

6. Watt C, Mitchell S and Salewski V: Bergmann's rule; A concept cluster? Oikos 119: 89-100, 2010

7. Lidell ME, Betz MJ and Enerbäck S: Two types of brown adipose tissue in humans. Adipocyte 3: 63-66, 2014.

8. Abdullahi A and Jeschke MG: White adipose tissue browning: A double-edged sword. Trends Endocrinol Metab 27: 542-552, 2016.

9. Lidell ME, Betz MJ and Enerbäck S: Brown adipose tissue and its therapeutic potential. J Intern Med 276: 364-377, 2014.

10. Fedorenko A, Lishko PV and Kirichok Y: Mechanism of fatty-acid-dependent UCP1 uncoupling in brown fat mitochondria. Cell 151: 400-413, 2012.

11. Blondin DP, Labbé SM, Tingelstad HC, Noll C, Kunach M, Phoenix S, Guérin B, Turcotte EE, Carpentier AC, Richard D and Haman F: Increased brown adipose tissue oxidative capacity in cold-acclimated humans. J Clin Endocrinol Metab 99: E438-E446, 2014.

12. Van der Lans AA, Wierts R, Vosselman MJ, Schrauwen P, Brans B and van Marken Lichtenbelt WD: Cold-activated brown adipose tissue in human adults: Methodological issues. Am J Physiol Regul Integr Comp Physiol 307: R103-R113, 2014.

13. Chondronikola M, Volpi E, Børsheim E, Porter C, Annamalai P, Enerbäck S, Lidell ME, Saraf MK, Labbe SM, Hurren NM, et al: Brown adipose tissue improves whole-body glucose homeostasis and insulin sensitivity in humans. Diabetes 63: 4089-4099, 2014.

14. Lee P, Smith S, Linderman J, Courville AB, Brychta RJ, Dieckmann W, Werner CD, Chen KY and Celi FS: Temperature-acclimated brown adipose tissue modulates insulin sensitivity in humans. Diabetes 63: 3686-3698, 2014.

15. Trayhurn P: Recruiting brown adipose tissue in human obesity. Diabetes 65: 1158-1160, 2016.

16. Kuperman Y, Weiss M, Dine J, Staikin K, Golani O, Ramot A, Nahum T, Kühne C, Shemesh Y, Wurst W, et al: CRFR1 in AgRP neurons modulates sympathetic nervous system activity to adapt to cold stress and fasting. Cell Metab 23: 1185-1199, 2016.

17. Shi SY, Zhang W, Luk CT, Sivasubramaniyam T, Brunt JJ, Schroer SA, Desai HR, Majerski A and Woo M: JAK2 promotes brown adipose tissue function and is required for diet- and cold-induced thermogenesis in mice. Diabetologia 59: 187-196, 2016.

18. Wilson MA, Grillo CA, Fadel JR and Reagan LP: Stress as a one-armed bandit: Differential effects of stress paradigms on the morphology, neurochemistry and behavior in the rodent amygdala. Neurobiol Stress 1: 195-208, 2015.

19. Loh K, Herzog H and Shi YC: Regulation of energy homeostasis by the NPY system. Trends Endocrinol Metab 26: 125-135, 2015.

20. Stanley BG, Magdalin W, Seirafi A, Nguyen MM and Leibowitz SF: Evidence for neuropeptide Y mediation of eating produced by food deprivation and for a variant of the $\mathrm{Y} 1$ receptor mediating this peptide's effect. Peptides 13: 581-587, 1992.

21. Chen P, Lin D, Giesler J and Li C: Identification of urocortin 3 afferent projection to the ventromedial nucleus of the hypothalamus in rat brain. J Comp Neurol 519: 2023-2042, 2011.

22. Liu X, Zhu Z, Kalyani M, Janik JM and Shi H: Effects of energy status and diet on Bdnf expression in the ventromedial hypothalamus of male and female rats. Physiol Behav 130: 99-107, 2014. 
23. Correll CM, Rosenkranz JA and Grace AA: Chronic cold stress alters prefrontal cortical modulation of amygdala neuronal activity in rats. Biol Psychiatry 58: 382-391, 2005.

24. Eshkevari L, Permaul E and Mulroney SE: Acupuncture blocks cold stress-induced increases in the hypothalamus-pituitary-adrenal axis in the rat. J Endocrinol 217: 95-104, 2013.

25. van-Hover C and Li C: Stress-activated afferent inputs into the anterior parvicellular part of the paraventricular nucleus of the hypothalamus: Insights into urocortin 3 neuron activation. Brain Res 1611: 29-43, 2015.

26. Mormède P, Castagné V, Rivet JM, Gaillard R and Corder R: Involvement of neuropeptide $\mathrm{Y}$ in neuroendocrine stress responses. Central and peripheral studies. J Neural Transm Suppl 29: 65-75, 1990

27. Lin S, Thomas TC, Storlien LH and Huang XF: Development of high fat diet-induced obesity and leptin resistance in C57Bl/6J mice. Int J Obes Relat Metab Disord 24: 639-646, 2000.

28. Shi YC, Lin S, Wong IP, Baldock PA, Aljanova A, Enriquez RF, Castillo L, Mitchell NF, Ye JM, Zhang L, et al: NPY neuron-specific $\mathrm{Y} 2$ receptors regulate adipose tissue and trabecular bone but not cortical bone homeostasis in mice. PLoS One 5: e11361, 2010

29. Lin S, Shi YC, Yulyaningsih E, Aljanova A, Zhang L, Macia L, Nguyen AD, Lin EJ, During MJ, Herzog H and Sainsbury A Critical role of arcuate Y4 receptors and the melanocortin system in pancreatic polypeptide-induced reduction in food intake in mice. PLoS One 4: e8488, 2009.

30. van den Pol AN, Yao Y, Fu LY, Foo K, Huang H, Coppari R, Lowell BB and Broberger C: Neuromedin B and gastrin-releasing peptide excite arcuate nucleus neuropeptide $Y$ neurons in a novel transgenic mouse expressing strong Renilla green fluorescent protein in NPY neurons. J Neurosci 29: 4622-4639, 2009.

31. Lin S, Boey D, Lee N, Schwarzer C, Sainsbury A and Herzog H: Distribution of prodynorphin mRNA and its interaction with the NPY system in the mouse brain. Neuropeptides 40: 115-123, 2006

32. McMillan AC and White MD: Induction of thermogenesis in brown and beige adipose tissues: Molecular markers, mild cold exposure and novel therapies. Curr Opin Endocrinol Diabetes Obes 22: 347-352, 2015.

33. Kuo LE, Czarnecka M, Kitlinska JB, Tilan JU, Kvetnanský R and Zukowska Z: Chronic stress, combined with a high-fat/high-sugar diet, shifts sympathetic signaling toward neuropeptide $\mathrm{Y}$ and leads to obesity and the metabolic syndrome. Ann N Y Acad Sci 1148: 232-237, 2008.

34. Pecoraro N, Reyes F, Gomez F, Bhargava A and Dallman MF: Chronic stress promotes palatable feeding, which reduces signs of stress: Feedforward and feedback effects of chronic stress. Endocrinology 145: 3754-3762, 2004.

35. Maniam $\mathbf{J}$ and Morris MJ: The link between stress and feeding behaviour. Neuropharmacology 63: 97-110, 2012.

36. Holzel BK, Carmody J, Evans KC, Hoge EA, Dusek JA, Morgan L, Pitman RK and Lazar SW: Stress reduction correlates with structural changes in the amygdala. Soc Cogn Affect Neurosci 5: 11-17, 2010

37. Haubensak W, Kunwar PS, Cai H, Ciocchi S, Wall NR, Ponnusamy R, Biag J, Dong HW, Deisseroth K, Callaway EM, et al: Genetic dissection of an amygdala microcircuit that gates conditioned fear. Nature 468: 270-276, 2010.

38. Alheid GF: Extended amygdala and basal forebrain. Ann N Y Acad Sci 985: 185-205, 2003.

39. Walker DL and Davis M: Double dissociation between the involvement of the bed nucleus of the stria terminalis and the central nucleus of the amygdala in startle increases produced by conditioned versus unconditioned fear. J Neurosci 17: 9375-9383, 1997.
40. Redrobe JP, Dumont Y, Fournier A, Baker GB and Quirion R: Role of serotonin (5-HT) in the antidepressant-like properties of neuropeptide Y (NPY) in the mouse forced swim test. Peptides 26: 1394-1400, 2005.

41. Husum H, Mikkelsen JD, Hogg S, Mathé AA and Mørk A Involvement of hippocampal neuropeptide $\mathrm{Y}$ in mediating the chronic actions of lithium, electroconvulsive stimulation and citalopram. Neuropharmacology 39: 1463-1473, 2000.

42. Zukowska-Grojec Z: Neuropeptide Y. A novel sympathetic stress hormone and more. Ann N Y Acad Sci 771: 219-233, 1995.

43. Qi J, Zhang S, Wang HL, Wang H, de Jesus Aceves Buendia J, Hoffman AF, Lupica CR, Seal RP and Morales M: A glutamatergic reward input from the dorsal raphe to ventral tegmental area dopamine neurons. Nature Commun 5: 5390, 2014.

44. Kuo LE, Kitlinska JB, Tilan JU, Li L, Baker SB, Johnson MD, Lee EW, Burnett MS, Fricke ST, Kvetnansky R, et al: Neuropeptide $\mathrm{Y}$ acts directly in the periphery on fat tissue and mediates stress-induced obesity and metabolic syndrome. Nat Med 13: 803-811, 2007.

45. Petrovich GD, Canteras NS and Swanson LW: Combinatorial amygdalar inputs to hippocampal domains and hypothalamic behavior systems. Brain Res Brain Res Rev 38: 247-289, 2001.

46. Xu B, Goulding EH, Zang K, Cepoi D, Cone RD, Jones KR, Tecott LH and Reichardt LF: Brain-derived neurotrophic factor regulates energy balance downstream of melanocortin-4 receptor. Nat Neurosci 6: 736-742, 2003.

47. Nakagawa T, Tsuchida A, Itakura $Y$, Nonomura T, Ono M, Hirota F, Inoue T, Nakayama C, Taiji M and Noguchi $H$ : Brain-derived neurotrophic factor regulates glucose metabolism by modulating energy balance in diabetic mice. Diabetes 49 : 436-444, 2000

48. Tsuchida A, Nakagawa T, Itakura Y, Ichihara J, Ogawa W, Kasuga M, Taiji M and Noguchi H: The effects of brain-derived neurotrophic factor on insulin signal transduction in the liver of diabetic mice. Diabetologia 44: 555-566, 2001.

49. Bromek E, Wójcikowski J and Daniel WA: Involvement of the paraventricular (PVN) and arcuate (ARC) nuclei of the hypothalamus in the central noradrenergic regulation of liver cytochrome P450. Biochem Pharmacol 86: 1614-1620, 2013.

50. Lee SK, Ryu PD and Lee SY: Differential distributions of neuropeptides in hypothalamic paraventricular nucleus neurons projecting to the rostral ventrolateral medulla in the rat. Neurosci Lett 556: 160-165, 2013.

51. Balbis A, Bartke A and Turyn D: Overexpression of bovine grow th hormone in transgenic mice is associated with changes in hepatic insulin receptors and in their kinase activity. Life Sci 59: 1363-1371, 1996.

52. Thirone AC, Carvalho CR, Brenelli SL, Velloso LA and Saad MJ: Effect of chronic growth hormone treatment on insulin signal transduction in rat tissues. Mol Cell Endocrinol 130: 33-42, 1997.

53. Mukherjee J, Baranwal A and Schade KN: Classification of Therapeutic and experimental drugs for brown adipose tissue activation: Potential treatment strategies for diabetes and obesity. Curr Diabetes Rev 12: 414-428, 2016.

This work is licensed under a Creative Commons Attribution-NonCommercial-NoDerivatives 4.0 International (CC BY-NC-ND 4.0) License. 